\title{
Screening for Major Depression in the Early Stages of Multiple Sclerosis
}

\author{
Michael J.L. Sullivan, Brian Weinshenker, Samuel Mikail and Scott R. Bishop
}

\begin{abstract}
Background: Multiple Sclerosis (MS) is associated with a high risk of developing major depression, but depression in MS patients frequently goes undetected and untreated. The current study examined the clinical utility of the Beck Depression Inventory (BDI) as a screening measure for major depression in newly diagnosed MS patients. Methods: Forty-six new referrals to an MS clinic completed the BDI and participated in a structured interview for major depression, within 2 months of the diagnosis of MS. Results: According to DSM-III-R criteria, $40 \%$ of patients were diagnosed with major depression, $22 \%$ had adjustment disorder with depressed mood, and 37\% showed no evidence of mood disorder. Sensitivity and specificity values, and positive and negative predictive values are reported for every BDI cut-off score between 9 and 21. Conclusions: A BDI cut-off score of 13 (sensitivity $=.71$, specificity $=.79$ ) is recommended as optimal for use in screening for major depression in newly diagnosed MS patients. The use of the BDI as a screening measure for major depression must proceed with caution given that a cut-off score of 13 still yielded a false-negative rate of $30 \%$.
\end{abstract}

RÉSUMÉ: Dépistage de la dépression majeure chez les patients en phase précoce de la sclérose en plaques. Introduction: La sclérose en plaques (SEP) est associée à un risque élevé de développer une dépression majeure, mais souvent la dépression n'est pas diagnostiquée ou traitée chez ces patients. Nous avons examiné l'utilité clinique du questionnaire de Beck (QB) comme outil de dépistage de la dépression majeure chez les patients ayant un diagnostic récent de SEP. Méthodes: Quarante-six patients nouvellement référés à une clinique de SEP ont complété le $\mathrm{QB}$ et ont participé à une entrevue structurée pour dépister la dépression majeure dans les 2 mois du diagnostic de SEP. Résultats: On a posé un diagnostic de dépression majeure selon les critères du LDSM-III-R chez $40 \%$ des patients. $22 \%$ avaient des difficultés d'adaptation avec une humeur dépressive et $37 \%$ ne présentaient aucun trouble de l'humeur. Nous rapportons la sensibilité et la spécificité de chaque valeur entre 9 et 21 utilisée comme valeur significative, ainsi que leur valeur prédictive positive et négative. Conclusions: Une valeur significative de 13 (sensibilité $=.71$, spécificité $=.79$ ) est recommandée comme étant optimale dans le dépistage de la dépression majeure chez les nouveaux cas de SEP. On doit cependant procéder avec discernement du fait qu'une valeur significative de 13 comportait un taux de faux-négatifs de $30 \%$.

Can. J. Neurol. Sci. 1995; 22: 228-231

Individuals with multiple sclerosis (MS) are at high risk for the development of major depression. Point prevalence rates of major depression in patients with MS range from 15\% to $36 \%$ using standardized diagnostic criteria. ${ }^{1-3}$ While most of the research has been conducted on MS patients with long standing illness, there are data to suggest that 30 to $40 \%$ of patients in the early stages of MS may also experience clinically significant depression..$^{4-6}$

Despite the high prevalence of major depression in patients with MS, depressive symptomatology may frequently go undetected and untreated. ${ }^{2}$ It has been estimated that as many as $50 \%$ of depressions may go undetected during standard medical evaluations. $^{7.11}$ A number of factors have been discussed as contributing to the underdiagnosis of depression in the physically ill. ${ }^{11-13}$ Patients may focus primarily on physical complaints during medical evaluations, directing the physician's attention away from emotional concerns, or physicians may avoid questions addressing depressive symptomatology during medical evaluations in order to avoid potential defensive reactions in their patients. Physicians may also consider patients' depressive symptoms to reflect "normal" adjustment reactions to their illness. This is particularly likely in the early stages of MS, where many patients may indeed experience uncomplicated adjustment reactions to the diagnosis of MS. ${ }^{6,14}$ However, if the depressive symptoms of newly diagnosed MS patients are construed as nonpathological reactions to chronic illness, then many patients with major depression will be denied the opportunity to receive appropriate treatment.

From the Departments of Psychology (S.R.B.) and Psychiatry, Dalhousie University, Halifax (M.J.L.S.); the Department of Neurology, Mayo Clinic, Rochester (B.W.); the Department of Psychology, The Rehabilitation Centre, Halifax (S.M.).

RECEIVED NOVEMBER 16, 1994. ACCEPTED IN FINAL FORM MARCH 22, 1995

Reprint requests to: Dr. M. Sullivan, Department of Psychology, Dalhousie University, Halifax, Nova Scotia, Canada B3H $4 \mathrm{JI}$ 
The DSM-III-R' 15 is considered the "gold standard" for psychiatric diagnostic criteria. According to the DSM-III-R, the symptoms considered for a diagnosis of major depression include depressed mood, loss of pleasure or interest, appetite and sleep disturbance, loss of energy, psychomotor agitation or retardation, excessive guilt, concentration difficulties, and suicidal ideation. The diagnosis of major depression is made when structured interview reveals that at least 5 of these symptoms have been present for a period of at least two weeks. Although it has been suggested that patients with chronic illness should be routinely evaluated for major depression, the resources needed to conduct structured interviews for affective disorders exceed the resources available in most clinical settings. ${ }^{6,11,12}$ Structured interviews for affective disorders must be conducted by a trained interviewer and they require in excess of 45 minutes to complete.

Because of their ease of administration and scoring, selfreport instruments such as the Beck Depression Inventory $(B D I)^{16}$ have been advocated as useful screening measures for major depression. ${ }^{11,12,17}$ However, when traditional cut-off scores are used, self-report measures of depression are typically associated with high rates of false-positive diagnoses, yielding prevalence rates of depression that are approximately twice as high as those based on diagnostic interviews. ${ }^{18-20}$ The potential for overdiagnosing depression may be even higher in medical populations since self-report measures of depression include somatic symptoms that overlap with symptoms of physical illness. " For example, although a cut-off of 9 on the BDI has been used in the general population to indicate clinically significant depression, a cut-off of 15 has been shown to be optimal in screening for depression in chronic low back pain patients, and a cut-off of 17 has been recommended in patients with end-stage renal disease. 12,21

Depression is associated with somatic symptoms that overlap with symptoms of MS. For example, lack of energy, motor slowing and sleep disturbance are common to both depression and MS. ${ }^{11,22.23}$ The BDI is heavily weighted for cognitive, affective, and behavioral symptoms of depression, with its total score not strongly related to somatic symptoms of depression. ${ }^{24}$ Several authors have commented that the relative lack of emphasis on somatic symptoms of depression makes the BDI particularly well suited for the measurement of depression in medical populations. ${ }^{11,12,20}$

The goal of the current study was to examine the utility of the BDI as a screening instrument for major depression in newly diagnosed MS patients. The utility of the BDI as a screening measure of major depression was addressed by comparing prevalence rates of depression made according to different BDI cut-off scores to diagnoses of major depression made according to DSM-III-R criteria. The utility of the BDI was examined by computing the sensitivity and specificity values, and positive and negative predictive values for every cut-off score of the BDI between 9 and 21 . Sensitivity refers to the probability that a patient with a diagnosis of major depression will score in the depressed range on a measure of depression. Specificity refers to the probability that a patient who does not have a diagnosis of depression will score in the non-depressed range on a measure of depression. While sensitivity and specificity values provide useful psychometric information about a screening measure, positive and negative predictive values provide more clinically relevant information. Positive predictive value refers to the proportion of individuals who score in the depressed range on the self-report measure and also receive a diagnosis of major depression. Negative predictive value refers to the proportion of individuals who score in the non-depressed range on the selfreport measure and do not have a diagnosis of major depression.

\section{MeTHODS}

\section{Subjects}

The sample consisted of 46 ( 36 women, 10 men) consecutive new referrals to the MS Clinic at the Ottawa General Hospital. All patients received diagnosis of probable or definite MS, and any patient that had previously received a diagnosis of MS was excluded from the sample. The mean age of the sample was 34.4 years. At the time of the assessment $64 \%$ of patients were married, and $53 \%$ were employed. Patients reported that their first symptoms began on average 2.9 years prior to diagnosis of MS.

\section{Procedure}

The clinic coordinator contacted all new referrals to the MS Clinic within six to eight weeks of their diagnosis, and asked them to participate in this research. Diagnoses of MS were made according to the Poser et al. ${ }^{25}$ criteria by one of four neurologists. Structured interviews using the Diagnostic and Interview Schedule; Affective Syndromes ${ }^{26}$ were conducted by one of four clinical psychologists. Diagnoses were made according to DSMIII-R criteria. ${ }^{15}$ The Beck Depression Inventory ${ }^{16}$ was also administered. The BDI consists of 21 items describing various symptoms associated with depression. The measure yields a total composite score reflecting level of depressive symptomatology.

\section{RESULTS}

Eighteen patients (40\%) met DSM-III-R criteria for major depression, and 10 patients $(22 \%)$ met the criteria for adjustment disorder with depressed mood. One patient was diagnosed with bipolar disorder, and 17 patients (37\%) were not depressed at the time of the interview. More detailed information on the relation between depression and MS in this sample is reported elsewhere. ${ }^{6}$

Figure I provides the sensitivity and specificity values for all BDI cut-off scores between 9 and 21 . Using the cut-off score of 9 suggested by Beck et al., ${ }^{17}$ the sensitivity of the BDI was .88 , and the specificity was .46 . In other words, $88 \%$ of patients with a diagnosis of major depression obtained BDI scores greater than or equal to 9 , but only $46 \%$ of patients without major depression scored below 9 on the BDI. Thus using a cut-off score of 9 yields an excessively high rate of false positive diagnoses.

The results suggest that a cut-off score of 13 may be optimal for using the BDI as a screening measure for major depression in newly diagnosed MS patients. A cut-off score of 13 yielded a sensitivity of .71 and specificity of .79 . With cut-off scores above 13 , sensitivity falls below .70 . Lower cut-off scores are associated with increased sensitivity, but considerably lower specificity. Table 1 presents positive and negative predictive values for the BDI for all cut-off scores between 9 and 21 . With a 


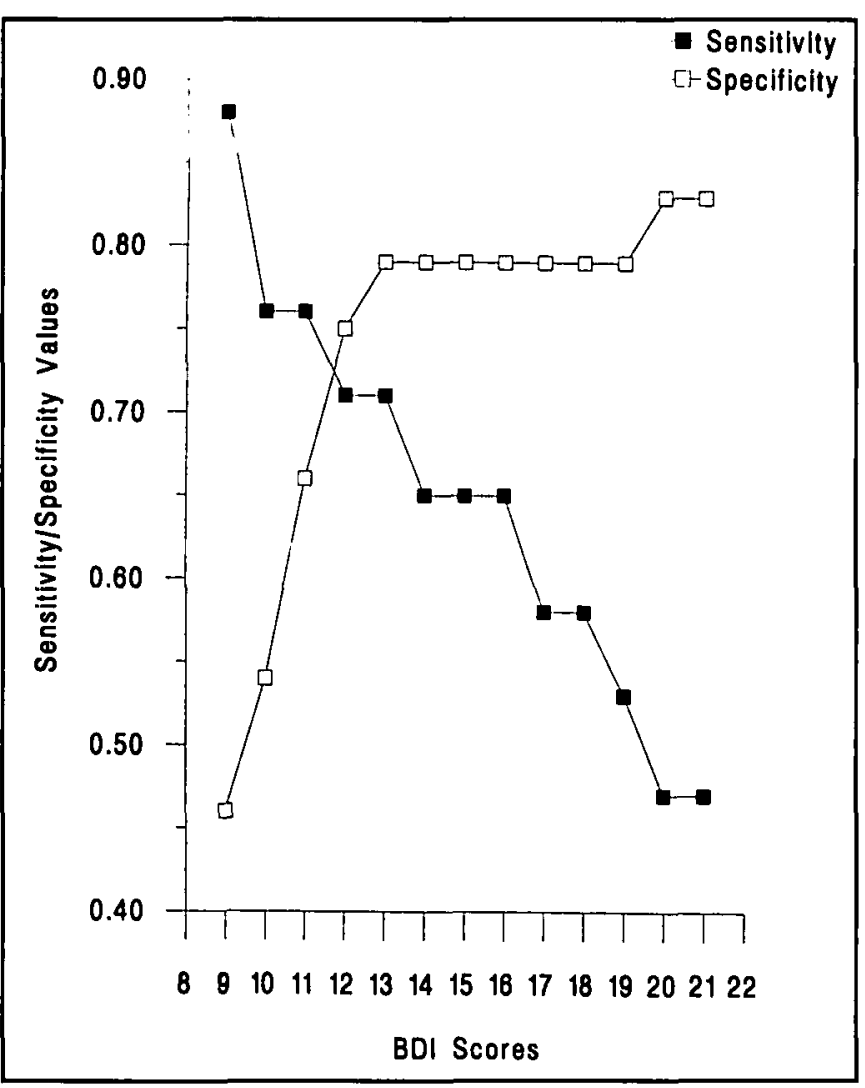

Figure 1: Sensitivity and Specificity Values for Different Cut-Off Scores of the BDI.

Table 1: Positive and Negative Predictive Values for Different Cut-Off Scores of the BDI.

\begin{tabular}{rrrrrrrrrrrrr}
\hline \multicolumn{11}{c}{ BDI Score } \\
\hline 9 & 10 & 11 & 12 & 13 & 14 & 15 & 16 & 17 & 18 & 19 & 20 & 21 \\
PPV .54 & .54 & .62 & .66 & .70 & .69 & .69 & .69 & .67 & .67 & .64 & .67 & .67 \\
NPV .84 & .76 & .80 & .78 & .79 & .76 & .76 & .76 & .73 & .73 & .70 & .69 & .69
\end{tabular}

Note: PPV $=$ Positive Predictive Value, NPV $=$ Negative Predictive Value.

cut-off score of $13,70 \%$ of patients who score within the depressed range on the BDI would meet DSM-III-R criteria for major depression. Similarly, 80\% who score below 13 on the BDI would not meet DSM-III-R criteria for major depression.

It has been suggested that one of the advantages of using the $\mathrm{BDI}$ in medical populations is that the BDI contains comparatively few somatic items with more than two thirds of items assessing cognitive-affective symptoms of depression. ${ }^{11}$ Separate scores were computed for the factorial subcomponents of the BDI. ${ }^{17}$ These included a) negative attitudes toward the self, b) performance impairment, and c) somatic disturbance. Patients with major depression obtained significantly higher scores than non-depressed patients on the negative attitudes toward the self, and performance subcomponents of the BDI, $F$ $(2,41)=3.98, p<.05$ and $F(2,41)=3.42, p<.05$, respectively. There were no significant group differences on the somatic subcomponent of the BDI, $F(2,41)=1.30$, ns. Multiple comparisons using the Newman Keuls procedure revealed that patients with adjustment disorder with depressed mood did not differ significantly from patients with major depression on any of the subcomponents of the BDI.

\section{Discussion}

It is becoming increasing clear that even in the early stages of MS, patients may experience depressive symptoms that are sufficient in number and severity to warrant a diagnosis of major depression. Unfortunately, MS clinics typically lack the resources necessary to assess all patients for affective disorders. The results of the current study suggest that the BDI may be used to screen for major depression in newly diagnosed MS patients. The BDI can be completed by patients in approximately 5 minutes and can be scored in less than one minute, thus facilitating its inclusion in standard clinical practice.

While the results of the current study support the clinical utility of the BDI as a screening measure for major depression in newly diagnosed patients with MS, its use must proceed with appropriate caution. The primary hazard concerns the percentage of patients with major depression who will score in the nondepressed range of the screening measure. The results of the this study indicate that using a BDI cut-off score of 13, approximately $30 \%$ of major depressions will go undetected. The number of false-negative diagnoses can be reduced by using a lower cut-off score, but the consequent increase in the number of false-positive diagnoses diminishes the advantage of using a screening measure. Clinicians need to weigh the disadvantages of missing cases of depression against the cost of increasing the rate of false-positive diagnosis. Given that $50 \%$ of depressions are likely to go undetected during medical evaluations, " a false-negative rate of $30 \%$ represents considerable improvement.

In a sample of patients with chronic low back pain, Bishop et al. ${ }^{12}$ reported that a BDI cut off score of 15 was optimal yielding sensitivity and specificity values of .80 and .70 , respectively. In the current sample, a cut off score of 15 yielded a sensitivity value of .79 , but a specificity value of only .63 . One factor contributing to the lower diagnostic indices is that the base rate of disorders associated with depressive symptoms, other than major depression, was higher in the current sample than in the sample described by Bishop et al. ${ }^{12}$ In other words, the diagnostic challenge for the BDI was greater in the current study given that cases of major depression had to be distinguished from cases of adjustment disorder with depressed mood. Symptom severity and symptom duration are the primary distinguishing characteristics of major depression and adjustment disorder with depressed mood. Untreated, major depression may persist for as long as one year and contribute to significant functional impairment, while adjustment disorder is expected to resolve within 6 months. In the Bishop et al. ${ }^{12}$ sample, there were no cases of adjustment disorder with depressed mood. These differences highlight the importance of determining optimal cut off scores for screening measures in specific medically ill populations.

The findings of the present study indicate that cognitive, affective, and behavioral symptoms of depression discriminate between depressed and non-depressed groups while somatic symptoms do not. It has been suggested that somatic items should be deleted from existing scales to make them more 
appropriate for medical populations. ${ }^{27}$ It is premature however to make strong recommendations to delete somatic items from the BDI for use in MS patients. The deletion of somatic items may risk underdiagnosing depression for depressed MS patients who present largely with somatic symptoms. Raising cut-off scores for case identification has the merit of minimizing the number of false-positive diagnoses due to overlapping somatic symptoms, without eliminating somatic symptoms from consideration. Furthermore, examination of the discriminant power of different BDI items would require more extensive psychometric analyses than were permitted by the sample size of the present study.

Several clinical reports that suggest that tricyclic antidepressants and cognitive-behavioral therapy may be effective means of managing depressive symptoms in patients with MS. ${ }^{28}$ Early identification and treatment of depression may help decrease the negative impact of MS symptoms and reduce depression-related disability. Routine screening for depression may alert clinicians to the need to address emotional factors related to illness, increase the treatment focus on depressive symptomatology in this population and ultimately increase patients' quality of life.

\section{ACKNOWLEDGEMENTS}

This research was conducted while the first author was supported by grants from the Royal Ottawa Health Care Group Foundation, the Social Sciences and Humanities Research Council of Canada, and Dalhousie University.

\section{REFERENCES}

1. Joffe RT, Lippert GP, Gray TA, Sawa G, Horvath Z. Mood disorders and multiple sclerosis. Arch Neurol 1987; 44: 376-378.

2. Minden SL, Orav J, Reich P. Depression in multiple sclerosis. Gen Hosp Psychiatr 1987; 9: 426-434.

3. Schiffer RB, Caine ED, Bamford KA, Levy S. Depressive episodes in patients with multiple sclerosis. Am J Psychiat 1983; 140: 1498-1500.

4. Lyon-Caen $\mathrm{O}$, Jouvent $\mathrm{R}$, Hauser $\mathrm{S}$, et al. Cognitive function in recent-onset demyelinating diseases. Arch Neurol 1988; 43: 1138-1141.

5. Millefiorini E, Padovani A, Pozilli C, et al. Depression in the early phase of MS: influence of functional disability, cognitive impairment and brain abnormalities. Acta Neurol Scand 1992; 86: 354358.

6. Sullivan MJL, Weinshenker B, Mikail S, Edgley K. Depression before and after diagnosis of multiple sclerosis. Mult Scler (in press).

7. Borus JF, Howes MJ, Devins NP, Rosenberg R, Livingston WW. Primary health care providers' recognition and diagnosis of mental disorders in their patients. Gen Hosp Psychiatr 1988; 10: 317321.

8. DePaulo JR, Folstein MF. Psychiatric disturbances in neurological patients: detection, recognition and hospital course. Ann Neurol $1978 ; 4: 225-228$.
9. Feldman E, Mayou R, Hawton K, Ardern M, Smith EB. Psychiatric disorder in medical inpatients. Quart J Med 1987; 63: 405-412.

10. Henley CE, Cousins WR. The ability of family practice residents to diagnose depression in outpatients. J Am Osteopath Assoc 1988; 88: $118-122$

11. Rodin G, Craven J, Littlefield C. Depression in the Medically III: An Integrated Approach. Brunner/Mazel, New York, 1991.

12. Bishop SR, Edgley K, Fisher R, Sullivan MJL. Screening for depression in chronic low back pain with the Beck Depression Inventory. Can J Rehab 1993; 7: 143-148.

13. Katon W, Egan K, Miller D. Chronic pain: Lifetime psychiatric diagnoses and family history. Am J Psychiatr 1985; 142: 11561160.

14. Brooks NA, Matson RR. Social-psychological adjustment to multiple sclerosis: a longitudinal study. Soc Sci Med 1982; 16: 2129. 2135.

15. American Psychiatric Association (1987). Diagnostic and Statistical Manual of Mental Disorders, 3rd Edition, Revised. American Psychiatric Association Press, Washington, DC.

16. Beck AT, Ward CH, Mendelson M, Mock J, Erbaugh J. An inventory for measuring depression. Arch Gen Psychiatr 1961; 4: 53-63.

17. Beck AT, Steer RA, Garbin MG. Psychometric properties of the Beck Depression Inventory: twenty-five years of evaluation. Clin Psychol Rev 1988; 1: 77-100.

18. Boyd JH, Weissman MM. Epidemiology. In: Paykel ES, ed. Handbook of Affective Disorders. New York: Guilford Press, 1982; 109-125.

19. Shapiro CM, Hamilton M. Depression. In: Peck DF, Shapiro CM, eds. Measuring Human Problems. A Practical Guide. Chichester: John Wiley, 1990; 49-72.

20. Sullivan MJL, Reesor K, Mikail S, Fisher R. The treatment of depression in chronic low back pain: review and recommendations. Pain 1992; 50: 5-13.

21. Rodin G, Voshart K. Depressive symptoms and functional impairment in the medically ill. Gen Hosp Psychiatr 1987; 9: 251-258.

22. Fisk JD, Pontefract A, Ritvo PG, Archibald CJ, Murray TJ. The impact of fatigue on patients with multiple sclerosis. Can J Neurol Sci 1994; 21: 9-14.

23. Clark CM, Fleming JA, Li D, et al. Sleep disturbance, depression, and lesion site in patients with multiple sclerosis. Arch Neurol 1992; 49: 641-643.

24. Louks J, Hayne C, Smith J. Replicated factor structure of the Beck Depression Inventory. J Nerv Ment Dis 1989; 177: 473-479.

25. Poser CM, Paty D, Scheinberg L, et al. New diagnostic criteria for multiple sclerosis: guidelines for research protocols. Ann Neurol 1983; 13: 227-231.

26. Robins LN, Helzer JE, Croughan J, Ratcliff KS. National Institute of Mental Health Diagnostic Interview Schedule: its history, characteristics and validity. Arch Gen Psychiatr 1981; 38: 381392.

27. Aylard PR, Gooding JH, McKenna PJ, Smith RP. A validation study of three anxiety and depression self-assessment scales. J Psychosom Res 1987; 31: 261-268.

28. Schiffer RB. Disturbances of affect. In: Rao S, ed. Neurobehavional Aspects of Multiple Sclerosis. New York: Oxford University Press, 1990. 